\title{
Construindo Instrumentos de Avaliação para os Cursos de Pós-Graduação Lato Sensu da Unifesp: relato de experiência
}

\author{
ISABEL CRISTINA KOWAL OLM CUNHA \\ Professora Adjunta da Universidade Federal de São Paulo e Presidente da \\ Subcomissão de Avaliação \\ icris@proex.epm.br \\ MARIA APARECIDA DE OLIVEIRA FREITAS \\ Mestre em Ciências pela Universidade Federal de São Paulo (Unifesp) \\ cida@proex.epm.br \\ LATIFE YÁZIGI \\ Professora Titular da Universidade Federal de São Paulo (Unifesp) \\ lyazigi@aclnet.com.br \\ LUIZ KULAY JUNIOR \\ Professor Titular da Universidade Federal de São Paulo (Unifesp) \\ kulay.toco@epm.br \\ MARCELO SAMPAIO DI PIETRO \\ Coordenador do Centro de Avaliação de Dados Institucionais da \\ Universidade Federal de São Paulo (Unifesp) \\ marcello@caidi.epm.br \\ MARIA ESTER DAL POZ \\ Coordenadora Executiva da Comissão Própria de Avaliação da \\ Universidade Federal de São Paulo (Unifesp) \\ ester.dalpoz@uol.com.br \\ JOSIANE GODOY \\ Pós-Graduanda em Gerenciamento de Serviços de Enfermagem da \\ Universidade Federal de São Paulo (Unifesp) \\ josiane_godoy@yahoo.com.br
}

\section{Resumo}

Este artigo relata a experiência de um grupo de professores para a construção de um sistema de avaliação para os cursos de Pós-Graduação Lato Sensu da Universidade Federal de São Paulo - Unifesp e apresenta as dimensões definidas durante as reuniões da subcomissão de Avaliação nomeada para esse fim. Com nove reuniões presencias no decorrer de 2006, e uso 
de mensagens eletrônicas, a subcomissão construiu três instrumentos para avaliar este segmento de nível superior: o perfil do ingressante, a avaliação dos cursos por alunos concluintes e um instrumento para egressos.

Palavras-chave: avaliação, avaliação de cursos, pós-graduação lato sensu, especialização, nível superior.

\title{
Resumen
}

Este artículo narra la experiencia de un grupo de profesores para construir un sistema de evaluación para los cursos de postgraduación Lato Sensu de la Universidad Federal de São Paulo - Unifesp - y presenta las dimensiones definidas durante las reuniones de la subcomisión de Evaluación designada para tal fin. Con nueve reuniones durante 2006 y el uso de mensajes electrónicos, la subcomisión construyó tres instrumentos para evaluar este segmento de nivel superior: el perfil de quien ingresa, la evaluación de los cursos por parte de alumnos que estaban terminando y un instrumento para quienes ya habían egresado.

Palabras-clave: evaluación, evaluación de cursos, postgrado lato sensu, especialización, nivel superior.

\begin{abstract}
This article reports on the experience of a group of teachers in building an evaluation system for the Continuing Education courses at the Universidade Federal de São Paulo - Unifesp, and presents the areas defined during the meetings of the Subcommittee of Evaluation. With nine actual meetings complemented by electronic messages, the subcommittee built three tools to assess this higher education segment: a beginner's profile, a course evaluation by finishing students and a tool for those who have completed the course.

Key words: evaluation, evaluation of courses, continuing education courses, specialization, higher education.
\end{abstract}




\section{INTRODUÇÃO}

No momento em que se discute a avaliação da Educação Superior, as Instituições de Ensino Superior - IES, acenam com um movimento para organizar seus processos de avaliação nos diferentes segmentos que a compõem - Graduação e Pós-Graduação Lato e Stricto Sensu. Porém, pensar e praticar a avaliação, cuja institucionalização das reflexões avaliativas ainda não se acha realizada (Gatti, 2006, p. 12), é um desafio que se coloca para todos os atores envolvidos e compromissados com os desdobramentos efetivos no contexto social do que é feito na universidade.

Dentre os diferentes significados atribuídos à palavra avaliação, privilegiamos aqueles que reforçam a importância que esta modalidade de ensino têm no cenário da educação no Brasil: determinar a valia ou valor de, reconhecer a força de (Ferreira, 1993, p. 58). É a partir dessas definições, e para legitimar a importância e as contribuições que a Pós-Graduação Lato Sensu tem no cenário socioeducativo, que a Universidade Federal de São Paulo Unifesp busca avaliar esses cursos, tomando como ponto de partida o conhecimento e a familiaridade da realidade a ser avaliada, amparando-se em referencial teórico que fundamente as discussões, as (des)construções e (re)constuções que envolvem os processos avaliativos e seus atores.

No início da década de 1980, as produções acadêmicas no âmbito da temática da Avaliação Institucional e da Avaliação da Educação Superior, tinham pouco destaque. Entretanto, com o crescente interesse pela avaliação da Educação Superior, evidencia-se, a partir dos anos 1990, um acelerado crescimento de publicações na área - principalmente a partir da segunda metade do período, que refletiam não só o interesse sobre o assunto, mas a centralidade desta temática no âmbito das reformas e das políticas públicas de educação ${ }^{1}$ (Brasil, 2003, p. 16).

Avaliar cursos e programas, tendo como elemento norteador a qualidade do que se produz nesses cursos, no seio da universidade, implica considerar as várias comunidades de referência que interagem com a universidade: a científica, a pedagógica (ligada aos processos formativos), a do trabalho, as civis, etc., que não são consideradas nos momentos de avaliação, em que, na maioria das vezes, se acumulam dados que não recebem a devida atenção como elementos importantes para mudanças, que permitem avanços socioeducacionais e culturais (Gatti, 2006, p.9).

1 Destaque para a revista Avaliação que, mesmo tendo surgido em 1996, concentra cerca da metade de toda a produção sobre Avaliação Institucional e Avaliação da Educação Superior no período de 1968-2000. 
No âmbito do Ministério da Educação, o Sistema Nacional de Avaliação da Educação Superior - Sinaes, instituiu a Comissão Especial de Avaliação - CEA, que tem por finalidade, analisar, oferecer subsídios, fazer recomendações, propor critérios e estratégias para a reformulação dos processos e políticas de avaliação da Educação Superior e elaborar a revisão crítica dos seus instrumentos, metodologias e critérios utilizados (Brasil, 2003, p. 7).

Assim, diante do importante papel que a educação superior tem na difusão, ampliação e aplicação do conhecimento, contribuindo para a constituição de uma sociedade mais eqüitativa (Gatti, 2006, p. 10), a Unifesp iniciou, em fevereiro de 2006, com a participação da Subcomissão de Avaliação, o desenvolvimento de instrumentos que permitissem avaliar os Cursos de Pós-Graduação Lato Sensu - Especialização, Aperfeiçoamento e MBA, uma vez que, até aquele momento, os cursos dessa modalidade oferecidos pela universidade, ainda não tinham sido avaliados.

\section{CONTEXTO DA AVALIAÇÃO: A UNIFESP}

Fundada em meados de 1933 por um grupo de idealistas, a Escola Paulista de Medicina - EPM era a décima primeira Escola de Medicina do país. Foi criada como uma instituição particular de ensino superior e transformada em estabelecimento público em 1956 (Silva, 1998, p.30).

Em 1994, por força da Lei n. 8.957, a então Escola Paulista de Medicina transforma-se na Universidade Federal de São Paulo - Unifesp, sendo a primeira universidade especializada na área da saúde no País, tendo como objetivo desenvolver, em nível de excelência, atividades de ensino, pesquisa e extensão, com ênfase no campo das Ciências da Saúde (Freitas, 2005, p.14).

Dentre os diferentes níveis de educação superior oferecidos por essa instituição de ensino, destacamos a pós-graduação Lato Sensu, com mais de 300 cursos de Especialização, Aperfeiçoamento e MBA em áreas como Saúde, Educação e Ciências Humanas, hoje com aproximadamente 2.400 alunos matriculados, que estão vinculados à Pró-Reitoria de Extensão PROEX, juntamente com as atividades de Extensão da Universidade (Universidade, 2004).

Propor um processo de avaliação para os cursos de Pós-Graduação Lato Sensu sempre foi uma preocupação dos membros da Comissão de Avaliação dos Cursos de Especialização - Coespa, Aperfeiçoamento e MBA. Porém, como era composta por muitos membros - professores de diferentes departamentos acadêmicos da Unifesp - optou-se por nomear uma subcomissão com número menor de participantes. 
Em fevereiro de 2006, o Pró-Reitor de Extensão, por meio de Portaria, cria o Grupo de Trabalho que recebeu o nome de Subcomissão de Avaliação, constituída por docentes dos Departamentos de Enfermagem, Psiquiatria e Obstetrícia, por uma Pedagoga que exerce a função de Coordenadora da Secretaria Escolar dos Cursos de Pós-Graduação Lato Sensu e por um Matemático que coordena o Centro de Avaliação e Integração de Dados Institucionais - Caidi da Unifesp. Como membros convidados, tivemos a colaboração da Coordenadora Executiva da Comissão Própria de Avaliação da Unifesp e uma aluna do Curso de Especialização em Gerenciamento de Serviços em Enfermagem.

Apesar da necessidade de avaliar a Pós-Graduação Lato Sensu, tinha-se consciência de que o instrumento de avaliação deveria atender às necessidades dos Coordenadores dos Cursos, alunos e Chefes de Departamento e Disciplinas, para que todos pudessem colaborar, pois o universo de cursos era muito grande e diferenciado. Assim, a busca de dimensões e indicadores que respondessem aos questionamentos, tanto dos discentes quanto dos docentes da universidade, foi o caminho trilhado pela Subcomissão de Avaliação.

Este trabalho tem como objetivo relatar o processo de construção de um sistema de avaliação para os Cursos de Pós-Graduação Lato Sensu na Unifesp, apresentando as dimensões avaliadas construídas durante as reuniões do Grupo de Trabalho.

\section{PERCURSO METODOLÓGICO}

A construção deste relato de experiência está pautada nos documentos elaborados pela Subcomissão de Avaliação dos Cursos de PósGraduação Lato Sensu no decorrer de seus encontros. A coleta de informações deu-se a partir de documentos e registros, atas e convocações das reuniões e dos instrumentos de avaliação produzidos pelo grupo.

A produção de conhecimento envolve uma forma de interrogar a realidade para compreendê-la, dando significado aos atos e estruturas sociais e apreendendo seus movimentos. Para MINAYO (1999), é uma atividade de aproximação sucessiva da realidade que nunca se esgota, fazendo uma combinação particular entre teoria e dados (p. 23).

A tarefa de construir instrumentos para avaliar este segmento de nível superior - ainda pouco avaliado - nos permitirá uma aproximação com a realidade pedagógica e estrutural dos cursos oferecidos nesta instituição, e envolveu um percurso metodológico dinâmico, constituído de 
nove encontros presencias e muitos diálogos e construções eletrônicas, no período de fevereiro a novembro do ano de 2006.

Inicialmente, as reuniões aconteceram quinzenalmente, e depois mensalmente. Nas primeiras reuniões, não havia a clareza do quê e como avaliar. Portanto, foi necessário definir as dimensões a serem avaliadas e os indicadores para cada uma delas. Estes foram os primeiros grandes desafios da Subcomissão de Avaliação que se debruçou sobre a realidade dos cursos oferecidos pela instituição para definir as dimensões.

Porém, para elaborar as dimensões e indicadores, os membros da subcomissão adotaram como estratégias fazer leituras fundamentadas em material a respeito de avaliação, distribuído para que cada um contribuísse com sugestões nessa construção. Esse material incluía artigos sobre avaliação, extraídos de diferentes periódicos nas áreas da Educação e também da Saúde; textos do Sinaes; instrumentos de avaliação utilizados por outras instituições e também pela própria Unifesp; documentos do Ministério da Educação - MEC e do Instituto Nacional de Estudos e Pesquisas Educacionais Anísio Teixeira - Inep, onde se pudesse obter informações consistentes sobre o tema.

As primeiras propostas para a avaliação deram conta que, naquele momento, seria interessante que os alunos concluintes pudessem avaliar a qualidade dos cursos, e que os egressos também participassem de um processo avaliativo, uma vez que, em dez anos de existência na Unifesp, esta modalidade de ensino não tinha passado por nenhuma avaliação. Avaliar a qualidade dos cursos implicava pensar nas questões pedagógicas, em uma auto-avaliação dos alunos, e nos recursos físicos e logísticos. A dimensão relacionada às questões pedagógicas mereceria então destaque, em que foram considerados como pontos importantes dentro desta dimensão: o currículo, a didática e a docência.

Assim, ao final da segunda reunião da Subcomissão de Avaliação, tinha sido construída a "árvore de dimensões I" para os Cursos de PósGraduação Lato Sensu da Unifesp, que tinha como objetivo avaliar a qualidade dos cursos, os egressos, as questões pedagógicas - no que tange ao docente, à didática e aos conteúdos curriculares - a auto-avaliação, e os recursos físicos e logísticos (Figura 1). 
Figura 1 - Árvore de Dimensões I

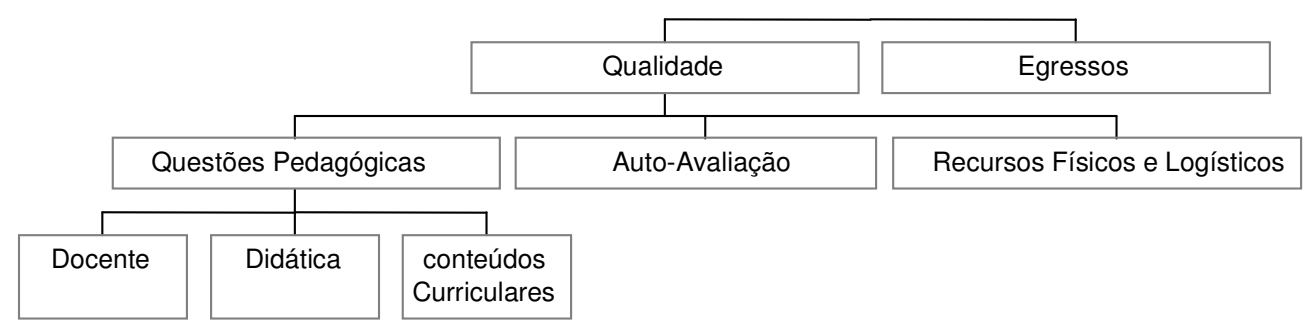

Para a dimensão egressos, era necessário avaliar a capacitação que o curso realizado proporcionou, e como esse profissional estaria colocado no mercado de trabalho atualmente, permitindo, assim, identificar marcas positivas da formação realizada no curso de especialização. O período escolhido para realizar a avaliação com os egressos foi de 1999 a 2005, e tinha como base o banco de dados dos ex-alunos já existente na instituição.

Os cursos de especialização hoje, no país, respondem por grande número de alunos que após a graduação procuram obter melhor qualificação para enfrentar o mercado de trabalho. Em razão de sua curta duração - mínimo de 360 horas e não exigência de prática - esta é a modalidade de pós-graduação mais procurada em diversas áreas (Brasil, 2001).

O encontro seguinte da subcomissão foi marcado por reflexões acerca da "árvore" no sentido de que suas dimensões deveriam ter início nos próprios cursos, e a partir daí estruturar-se "o quê" dentro da qualidade deveria ser avaliado. Discutiu-se ainda, a necessidade de se traçar o perfil do ingressante que procura a Unifesp para realizar esses cursos, e finalmente os egressos.

A definição dessas dimensões não foi tarefa fácil e sua construção implicou muitas negociações dentro do grupo. Assim, a cada reunião, somadas às reflexões e experiências com a coordenação de cursos, por parte de alguns docentes, as dimensões da árvore eram aprimoradas e receberam numeração I, II, III e IV. Nas "árvores" de números II e III, mantivemos as mesmas dimensões da primeira; porém, sentimos necessidade de renomear algumas das dimensões já determinadas até para que pudéssemos acoplar outras questões a elas. Dessa maneira, as árvores II e III tinham como foco avaliar os cursos no que dizia respeito a: traçar o perfil dos ingressantes, a qualidade dos cursos e sua estrutura, tanto pedagógica (conteúdos curriculares, auto-avaliação, didática e o docente) como de recursos físicos 
e logísticos, e os egressos, especificamente no que diz respeito à capacitação profissional.

A "árvore" de número IV foi a que norteou a construção da avaliação, bem como dos instrumentos utilizados no processo a partir do estabelecimento dos diferentes indicadores, discutidos a seguir (Figura 2).

Figura 2 - Dimensões da Avaliação IV

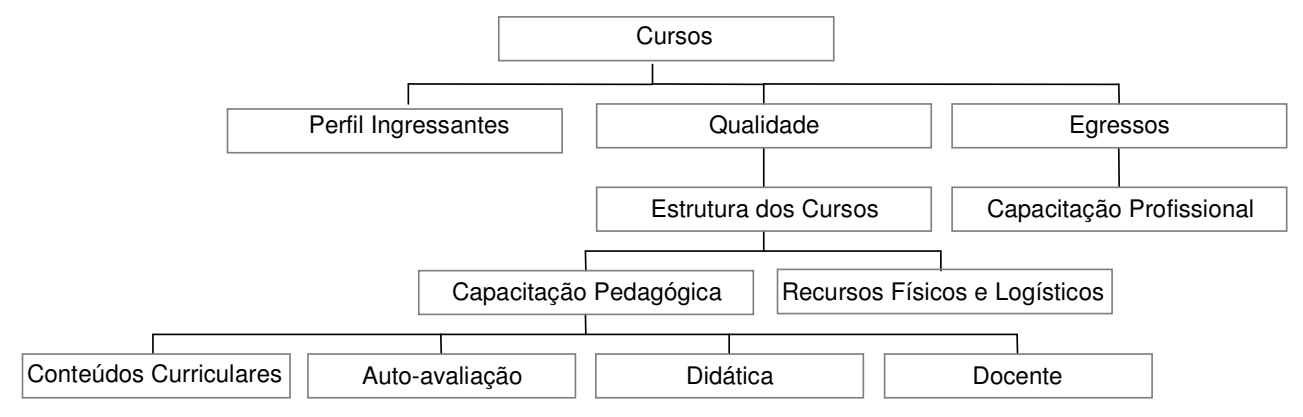

A figura 2, mostra as três dimensões que foram privilegiadas no processo avaliativo descrito para os Cursos de Especialização Lato Sensu.

Desse modo, traçar o perfil dos ingressantes constituiu a parte inicial do processo, a fim de caracterizar o público que procura essa universidade para melhorar sua qualificação profissional. Para este segmento, destacaram-se os dados de identificação de quem procurava a Unifesp. É importante situar que as informações referentes ao perfil dos ingressantes fazem parte da ficha de inscrição que o candidato preenche quando vai se inscrever nos cursos, e que está disponível na internet, especificamente na página da Pró-Reitoria de Extensão - Proex.

Na segunda dimensão, é dado destaque à qualidade que objetivou avaliar, na estrutura dos cursos analisados, a capacitação pedagógica e os recursos físicos e logísticos utilizados para o seu desenvolvimento. Há que salientar, quanto aos desdobramentos da capacitação pedagógica, onde se podem avaliar os conteúdos curriculares, a didática utilizada pelo corpo docente, o docente e a auto-avaliação do aluno no decorrer do curso. Essa dimensão - a mais ampla de todo o contexto - era necessária para trazer respostas que contribuíssem para a melhoria da política institucional para esse nível de ensino e também para que os coordenadores dos cursos pudessem promover mudanças em sua estrutura didático-pedagógica. 
Finalmente, na dimensão egressos, procurou-se entender o impacto que o curso realizado teve na capacitação profissional dos alunos. Todavia, é preciso destacar que esse aspecto talvez seja difícil de ser avaliado, em razão das dificuldades em localizar os ex-alunos, pois muitos endereços que constam no banco de dados estão desatualizados. Entretanto, de posse dos nomes desses egressos, pretende-se realizar um trabalho de coleta de dados em órgãos de classe para que se possa, na medida do possível, obter informações sobre esses profissionais.

\section{CONCLUSÃO}

Trabalhar em equipe implicou muitas negociações e mediações, pois construir coletivamente instrumentos de avaliação, levando-se em consideração a diversidade dos cursos que a Unifesp ministra e a experiência de cada um dos membros do grupo, foi uma tarefa enriquecedora para todos e uma verdadeira construção de conhecimento.

Durante os encontros, as reflexões sobre o tema foram o marco principal dessa construção, sendo fundamentais para a elaboração de idéias, permitindo pensar nas práticas docentes e nas funções administrativas que muitas vezes são desempenhadas no âmbito da universidade - e que também tiveram sua importância neste processo.

Assim, no grupo, ao se construir o processo avaliativo, refletiu-se, ainda, sobre a impossibilidade de separar as ponderações a respeito da avaliação e as práticas docentes que muitos desenvolviam. As dificuldades enfrentadas como professores e coordenadores de cursos foram muito importantes para alavancar o trabalho, pois saberes, práticas, intenções e dúvidas sinalizaram os primeiros desafios a vencer para a construção dos instrumentos.

A tarefa de avaliar é, portanto, complexa. Nunca se consegue abranger todos os aspectos que merecem ser avaliados e compatibilizá-los com o tamanho dos instrumentos é importante para que possa haver adesão dos alunos.

Sensibilizar os respondentes para esta tarefa também é importante e fundamental para seu sucesso. Analisar e incorporar as sugestões pertinentes para a melhoria dos cursos é outro aspecto que merece destaque, pois o avaliador no curso - o aluno - quer ter certeza que suas considerações serão levadas em conta.

Na Unifesp, ainda há muito que ser desenvolvido no nível da avaliação dos cursos Lato Sensu. A perspectiva de se localizarem todos os egressos desde 1996 é uma meta a ser perseguida nesta etapa do processo, 
pois sabemos que esta avaliação muito contribuirá para que a universidade reconheça, neste nível de ensino, seu importante papel na qualificação de profissionais.

Assim, o compartilhar desta experiência, muito singular para o grupo que a vivenciou, objetivou oferecer propostas para o debate, bem como para o enriquecimento da temática em questão.

É importante ressaltar que este processo de avaliação encontra-se em execução desde fevereiro de 2007, quando o questionário que avalia os cursos nas dimensões descritas anteriormente foi disponibilizado no site da Proex, onde os alunos, por meio de acesso específico, podem respondê-lo. Em seis meses, desde que foi disponibilizado, o sistema acumulou respostas de cerca de $25 \%$ dos alunos concluintes. Isso demonstra a importância desta avaliação neste segmento de ensino nunca avaliado anteriormente na Unifesp.

\section{REFERÊNCIAS BIBLIOGRÁFICAS}

BRASIL. Sistema Nacional de Avaliação da Educação Superior: bases para uma nova proposta de avaliação da Educação Superior Brasileira. Brasília: MEC/Inep, 2003. Disponível em: <http://www.publicacoes.inep.gov.br/detalhes. asp?pub=3608> Acesso em: 25 abr. 2007.

BRASIL. Conselho Nacional de Educação. Resolução n. 1 de 03 de abril de 2001. Disponível em: <http://portal.mec.gov.br/sesu/index.php?option= content\&task=view\&id=769\&Itemid=306> Acesso em: 26 abr. 2007.

FERREIRA, A. B. H. Minidicionário da Língua Portuguesa. Rio de Janeiro: Nova Fronteira, 1993.

FREITAS, M. A. O. Pós-Graduação e Formação Docente: a experiência da Disciplina de Formação Didático-Pedagógica em Saúde na Unifesp. São Paulo, 2005. Dissertação (mestr.) Universidade Federal de São Paulo. Centro de Desenvolvimento do Ensino Superior em Saúde - Cedess.

GATTI, B. A. Avaliação Institucional: processo descritivo, analítico ou reflexivo? Estudos em Avaliação Educacional. São Paulo: Fundação Carlos Chagas, v. 17, n. 34, p. 7-14, maio/ago. 2006.

MINAYO, M. C. S. O Desafio do Conhecimento: pesquisa qualitativa em saúde. 6.ed. São Paulo: Hucitec, 1999. 
SILVA, M. R. B. Construindo uma instituição: Escola Paulista de Medicina (1933-1956). São Paulo, 1998. Dissertação (mestr.) Universidade de São Paulo. Departamento de História da Faculdade de Filosofia, Letras e Ciências Humanas.

UNIVERSIDADE FEDERAL DE SÃO PAULO - Unifesp. Relatório de Atividades do Primeiro Ano de Gestão 2003-2007. São Paulo, 2004. Disponível em: <www.unifesp.br/reitoria/gestao> Acesso em: 13 jan. 2007.

Recebido em: agosto 2007

Aprovado para publicação em: dezembro 2007 
